\title{
Whole body irradiation and agonist anti-CD40 synergize to promote adoptive T cell therapy of resistant murine pancreatic neuroendocrine tumors
}

\author{
Lindsay Ward-Kavanagh, Timothy K Cooper, Aron Lukacher, Todd D Schell \\ From 30th Annual Meeting and Associated Programs of the Society for Immunotherapy of Cancer (SITC 2015) \\ National Harbor, MD, USA. 4-8 November 2015
}

\section{Background}

Adoptive $\mathrm{T}$ cell therapy (ACT) can promote dramatic regressions of established cancer, yet durable clinical responses are observed in only a subset of patients. ACT provides the opportunity to alter the immune suppressive host environment associated with cancer prior to introduction of tumor-specific $\mathrm{T}$ cells.

\section{Methods}

Here, we evaluated the utility of combined whole body irradiation and agonist anti-CD40 antibody to enhance ACT-mediated control of established autochthonous pancreatic tumors.

\section{Results}

Sublethal whole body irradiation, a conditioning regimen associated with donor $\mathrm{T}$ cell persistence, had little impact on donor $\mathrm{T}$ cell magnitude or disease outcome, but did increase T cell persistence. Anti-CD40 conditioning, an approach known to enhance antigen presenting cell function and $\mathrm{T}$ cell expansion, transiently increased $\mathrm{T}$ cell accumulation in the lymphoid organs and the pancreas, but failed to eliminate established disease. In contrast, combined whole body irradiation and anti-CD40 prolonged $\mathrm{T}$ cell proliferation in the tumor draining lymph node and dramatically increased accumulation of interferon gamma-producing, $\mathrm{PD}-\mathrm{1}^{\mathrm{lo}}$ donor $\mathrm{T}$ cells in the pancreas. Dual-conditioning with ACT also induced histologic regression of established tumors and significantly increased overall survival. Increased lifespan was entirely dependent upon $\mathrm{T}$ cell transfer, and partially dependent upon interferon gamma production by donor $\mathrm{T}$ cells.

\section{Conclusions}

Our results identify the novel combination of two clinically relevant host conditioning approaches that together with ACT overcome tumor-induced immune suppression to produce dramatic therapeutic benefits against established tumors.

\section{Acknowledgements \\ This work was supported by research grants R01 CA025000 from the National Cancer Institute, National Institutes of Health (to TDS) and R01 Al102543 from the National Institute of Allergy and Infectious Diseases, National Institutes of Health (to AEL). LKW was supported by predoctoral training grant T32 CA060395 from the National Cancer Institute, National Institutes of Health.}

Published: 4 November 2015

\section{doi:10.1186/2051-1426-3-S2-P50}

Cite this article as: Ward-Kavanagh et al:: Whole body irradiation and agonist anti-CD40 synergize to promote adoptive T cell therapy of resistant murine pancreatic neuroendocrine tumors. Journal for ImmunoTherapy of Cancer 2015 3(Suppl 2):P50. 